\title{
EOSINOPHILIA WITH SPECIAL REFERENCE TO HELMINTHIASIS
}

\section{By}

EMAN EBRAHIM ABDEL FADIL ${ }^{1}$, MOUSA ABDEL GAWAD M. ISMAIL ${ }^{2}$ and TOSSON A. MORSY ${ }^{3}$

Military Medical Academy Cairo $11291^{1}$ and Departments of Parasitology, Faculties of Medicine, Cairo University ${ }^{2}$ and Ain Shams University, Cairo $11566^{3}$, Egypt

\section{Abstract}

Eosinophilia (e-o-sin-o-FILL-e-uh) is a higher than normal level of eosinophils. Eosinophils are a type of disease-fighting white blood cell, indicating a parasitic infection, an allergic reaction or cancer. There are blood eosinophilia and tissue eosinophilia.

Tissue eosinophilia may be found in samples taken during an exploratory procedure or in samples of certain fluids, such as mucus released from nasal tissues. If you have tissue eosinophilia, the level of eosinophils in your bloodstream is likely normal. Blood eosinophilia may be detected with a blood test, usually as part of a complete blood count. More than 500 eosinophils per microliter of blood is generally considered eosinophilia in adults. More than 1,500 eosinophils per microliter of blood that lasts for several months is called hypereosinophilia. This reviewed the correlation between high eosinophila and helminthiasis.

Key words: Eosinophilia, Helminthiasis, Organic diseases, Health disorders

\section{Introduction}

A great variety of allergic, infectious, neoplastic, and idiopathic diseases are associated with increased blood and/or tissue eosinophilia and range in severity from self-limited conditions to life-threatening disorders. The major causes of blood and tissue eosinophilia are many diseases and health disorders. These are allergic diseases, atopic and related diseases (Noh et al, 2010), medication-related eosinophilias, infectious diseases, parasitic infections, mostly helminthes (Liu et al, 2004), specific fungus, other infections (infrequent), hematologic and neoplastic disorders, hypereosinophilic syndrome, leukemia, lymphomas (Samoszuk et al, 1993), tumor-associated (Szor et al, 2018), mastocytosis and diseases with specific organ involvement, skin and subcutaneous diseases, pulmonary diseases, gastrointestinal diseases, neurologic diseases, rheumatologic diseases (Samoszuk and Nansen, 1990), cardiac diseases, renal diseases, immunologic reactions, specific immune deficiency diseases (Paganelli et al, 1995), transplant rejection, endocrine and hypoadrenalism.

Considerations and Discussion

Given the diversity of medical conditions that may be associated with increased blood eosinophilia, the evaluation of such patients must include consideration of diverse medi- cal conditions that may contribute to eosinophilia. Blood eosinophilia is labile, and absolute thresholds for many clinical conditions cannot be definitively established. In asthma, eosinophils levels were usually less than $1500 / \mathrm{mm}^{3}$ (Bass et al, 1980). In ChurgStrauss Syndrome (often with asthma), however, blood eosinophil levels were greater than $1500 / \mathrm{mm}^{3}$. Low levels of blood eosinophils were found in the setting of eosinophil-mediated cardiac damage (Blauwet $e t$ al, 2005). But, sustained elevated levels of blood eosinophilia should prompt ongoing pursuit of an etiology for eosinophilia and monitoring for organ-associated damage.

Definitions: Although accepted upper limits of normal blood eosinophil numbers vary somewhat, a value above 500 eosinophils/microL of blood is abnormal in the vast majority of cases (Roufosse and Weller, 2010). Eosinophilia degree was categorized into mild (500 to 1500 cells/microL), moderate (1500 to 5000 cells/microL) or severe (>5000 cells/microL). Term "hypereosinophilia" refers to eosinophil levels $>1500 /$ microL, which can be associated with tissue and organ damage, regardless of underlying cause. Term "hypereosinophilic syndrome" has been variously defined, with one proposal being the presence of an eosinophil count $>1500 /$ microL in absence of a discern- 
able secondary cause e.g., allergic diseases, drug hypersensitivity, parasitic helminthes, HIV-infection, nonhematologic malignancies (Simon et al, 2010).

Categories of eosinophilia: Peripheral eosinophilia can be divided into categories of primary, secondary, or idiopathic one (Tef feri, 2005).

Primary eosinophilia usually occurs in the context of hematologic malignancies, such as acute leukemias or chronic myeloid disorders, when there is evidence of clonal expansion of eosinophils.

The most common infectious cause for secondary eosinophilia is the tissue invasive parasite. Noninfectious causes of secondary eosinophilia include allergic disorders, medications, toxins, autoimmune diseases, and endocrine disorders, such as Addison's disease. Eosinophils can occur in Hodgkin's \& non-Hodgkin lymphoma and other metastatic cancers, but the associated eosinophils are not of a clonal nature in this situation.

A diagnosis of idiopathic eosinophilia is considered when a thorough evaluation does not identify either a primary or secondary cause of eosinophilia. Hypereosinophilic syndromes (HES) are a group of disorders marked by sustained overproduction of eosinophils, in which eosinophilic infiltration and mediator release cause damage to multiple organs (Sheikh and Weller, 2007). Although these disorders had long been considered idiopathic (e.g., as in "idiopathic hypereosinophilic syndrome", IHES), etiologies for some forms of HES have now been described. HES are a heterogeneous group of disorders, encompassing a number of etiologically distinct diseases. Underlying molecular or immunologic defects can be identified in about $25 \%$ of cases. Diagnosis of HES should be suspected in patients with sustained blood eosinophilia of $\geq 1500$ / microliter, documented on at least two occasions, no other apparent etiologies for eosinophilia, and often signs and/or symptoms of end-organ dysfunction. HES are commonest in patients 20-50 years of age. FIP1L1-
PDGFRalpha-associated variant affects mostly males, whereas other variants appear to affect males and females in roughly equal proportions. Important subtypes include myeloproliferative variants, $\mathrm{T}$ cell lymphocytic variants, and familial eosinophilia. These subtypes are associated with a more clearlydefined clinical presentation and prognosis, and in the case of FIP1L1-PDGFRA associated myeloproliferative variant, response to specific therapies. Other complex forms of HES have still-uncertain etiologies, yet represent the bulk of subjects with HES and may be difficult to distinguish from other eosinophil-associated disorders, including CSS vasculitis. Organ systems most commonly affected in HES are the heart, nervous system, skin, lungs, and gastrointestinal tract. Patients with HES might be present with gradually progressive symptoms, or with life-threatening cardiac and neurologic events, such as thromboembolic stroke or encephalopathy. Once secondary causes of eosinophilia are excluded, patients with persistent eosinophilia must be con-sidered as possible HES and evaluated accordingly, regardless of the presence or absence of symptoms. This evaluation involves an assessment of end-organ involvement and specialized studies to identify patients with myeloproliferative or clonal lymphocytic variants (Bain and Fletcher, 2007).

Patient evaluation: Blood eosinophilia most commonly reflects an allergic, infectious, or neoplastic process. A thorough examining of a patient with eosinophilia needed consideration of the patient's history, physiccal examination, laboratory information and imaging studies (Brito-Babapulle, 2003).

In initial evaluation, information regarding allergic symptoms, international travel, current and recent medications, and constitutional symptoms should be sought. If the medication and allergy history is unrevealing, three stool specimens must be examined for ova and parasites. In the setting of international travel or other geographic exposures to helminthic parasites, then more 
work-up including serologic tests depended on the geographic area that the patient visited (Lombardi and Passalacqua, 2003). Those with symptoms consistent with allergic rhinitis may be diagnosed by examination of a nasal smear for eosinophils. Those with a suspected clonal disorder will need a hematologic evaluation.

Medication-related eosinophilia: Administration of many conventional or alternative medications may produce eosinophilia; thus, a detailed history of current or past medication use is required when evaluating a patient with this condition.

The attribution of eosinophilia to a specific medication were identified in many drug reqactions 1- Cytokine-mediated as GM-CSF, IL-2, 2- Pulmonary infiltrates as Non-steroidal antiinflammatory agents, 3- Pleuro-pulmonary as Dantrolene, 4- Interstitial nephritis as Semisynthetic penicillins, cephalosporins, 5- Necrotizing myocarditis as Ranitidine, 6- Hepatitis as semisynthetic penicillins, tetracyclines, 7- Hypersensitivity vasculitis as Allopurinol, phenytoin 8- Gastroenterocolitis as Nonsteroidal anti-inflammatory agents, 9- Asthma, nasal polyps as Aspirin, 10- Pharmacologic as Beta blockers, 11- Eosinophilia-myalgia syndrome as L-tryptophan contaminant, and 12- Asymptomatic as ampicillin, penicillins, cephalosporins. Blood eosinophilia by itself need not necessitate cessation of drug therapy but must lead to an evaluation of organs likely to be involved in eosinophil-associated drug reactions, including the lungs, kidneys, and heart (Weller, 1991).

Infectious Diseases: Most acute bacterial or viral infections characteristically produce eosinopenia. Even in patients with eosinophilia due to parasitic or allergic diseases, the development of intercurrent bacterial or viral infections leads to suppression of blood eosinophilia until the superimposed acute infection has resolved. Thus, heightened or even normal blood eosinophil numbers in a febrile patient should prompt consideration of a noninfectious cause, such as an eosino- philic syndrome-related illness or adrenal insufficiency. The mechanisms responsible for infection-related eosinopenia have not been precisely delineated but the phenomenon probably is due to heightened endogenous corticosteroid production and the actions of various inflammatory mediators (Jenerowicz et al, 2007).

Parasitic infections: Eosinophilia is prominent in a number of helminthic parasitic diseases. Eosinophilic response to helminths is determined both by host's immune response and by the parasite, including its distribution, migration, and development within the infected host. Level of eosinophilia parallels the magnitude and extent of tissue invasion by helminthic larvae or adults. The height of the eosinophilia peaks early in the course of infection with several helminthes since the migration of larvae is greatest at this time (Tab. 1). But, absence of eosinophilia does not exclude the presence of these parasites.

For established infections, tissue eosinophilia around helminths may not be accompanied by blood eosinophilia when the organism is antigenically sequestered within tissues (e.g., intact echinococcal cysts) or is limited solely to the intestinal lumen (e.g., tapeworms or adult Ascaris roundworms). Intermittent leakage of fluids from echinococcal cysts were transiently stimulated increase in blood eosinophilia and elicit urticaria, bronchospasm, or anaphylaxis (Georgiou et $a l, 2005)$. Several helminthes can lead to long-lasting eosinophilia (Tab. 2).

Infections with a diversity of helminthic parasites elicit eosinophilia via stimulation of Th2-like lymphocyte responses (Liu et al, 2004). TH2 response is characterized by production of IL-4 \& IL-5, subsequently generating IgG1 \& IgE-secreting cells, and eliciting eosinophilia.

Diagnosis: Amongst helminthes, the main parasites that need to be evaluated are Strongyloides stercoralis, hookworm, filariae, and Toxocara canis. The diagnostic value can also vary according to geographic origin. In 
128 Indochinese patients, eosinophilia was not find by routine screening (Nutman et al, 1987). Hookworm (55\%) and S. stercoralis (38\%) were the most common organisms identified. In contrast, in African Immigrants the commonest parasites were $30 \%$ in filariae, $17 \%$ in each schistosomes or hookworm and $8 \%$ in whipworms (Pardo et al, 2006).

The following caveats must be considered when evaluating a patient with eosinophilia: a- Fascioliasis is a zoonotic foodborne trematode caused by Fasciola spp. that are flat leaf-like worms known as liver flukes. Two species that infect man are $F$. hepatica and Fasciola gigantica. Ectopic of immature flukes involved subcutaneous tissue, intestinal wall, lungs, pancreas, eye, brain, stomach wall, pharyngeal mucosa, skin and others were very rare (Rashed et al, 2010). Eosinophilic pneumonia can be caused aside from Fasciola spp., by others, especially Ascaris, Strongyloides, Paragonimus, Trichinella, and Toxocara (Bhatt and Allen, 2012). With the exception of helminthiasis, the secondary causes of eosinophilia rarely cause an absolute eosinophil count of $>1500$ cells/ $\mathrm{mm}^{3}$. Parasites which cause tissue invasion resulted in extreme eosinophilia (Bayhan et $a l, 2016)$. The commonest abnormalities of fascioliasis were the increased levels of total $\mathrm{IgE}$, total $\mathrm{IgG}$, leukocytosis and eosinophilia elevations in the erythrocyte sedimentation rate (Kaya et al, 2011). Other most prominent liver flukes are Clonorchis sinensis, Opisthorchis felineus and O. viverrini (Fürst et al, 2012). Hwang et al. (2012) in Korea stated that $C$. sinensis should be considered as a cause of multiple microembolic stroke associated with idiopathic hypereosinophilic syndrome. This fluke invaded Egypt with immigrant workers back from Saudi Arabia (Morsy and Al-Mathal, 2011).

Gryseels et al. (2006) reported that in chronic schistosomiasis, immunopathologic reactions against tissues trapped eggs led to inflammatory and obstructive disease in urinary system ( $S$. haematobium) or intestinal disease, hepatosplenic inflammation, and liver fi- brosis (S. mansoni and S. japonicum).

b- Strongyloides spp. can persist for decades without causing major symptoms. The infection elicits varying degrees of eosinophilia ranging from minimal to such high magnitude that it was mistaken for a hypereosinophilic syndrome. Disseminated fatal disease (hyperinfection syndrome) developed in patients unsuspectingly given corticesteroids and/or immune-suppressive therapies (Nucci et al, 1995). In the patient with eosinophilia, serology proved useful to detect strongyloidiasis when fecal examinations are unrevealing (Gill and Bailey, 1989).

In strongyloidiasis developing hyperinfection syndrome increased if cell-mediated immunity was impaired by congenital immunodeficiency, underlying malignancy, malnutrition, alcoholism, hematopoietic stem cell transplantation (HSCT), or corticosteroids or cytotoxic drugs administration (Keiser and Nutman, 2004). The pathophysiology underlying these risk factors, whether disease-related or iatrogenically induced, is a compromised immune system leading to dysfunction of $\mathrm{TH}-2$ helper cells, and thus eradicated infection prior to initiation of immunosuppressive therapy (Concha et al, 2005). But, whether this effect was sufficient or not to reduce the risk of hyperinfection in patients receiving cyclosporine? Patients with HTLV-1 infection have high levels of interferon-gamma production, which decreases the production of IL-4, IL5 , IL-13, \& IgE, important molecules in host defense against strongyloidiasis (Carvalho and Porto, 2004). Disseminated strongyloidiasis can occur in patients with AIDS but less frequently than in patients with HTLV-1 and is much less common than might be predicted given the coendemicity of the two infections (Kim and Lupatkin, 2004). But, immune reconstitution might be a risk factor for strongyloidiasis dissemination (Brown et $a l, 2006)$ and in HIV positive patients at risk for strongyloidiasis treatment failure (Viney et al, 2004). Other conditions or medications may be associated with strongyloidiasis in- 
creased risk: hypogammaglobulinemia, antiTNF receptor therapy (Krishnamurthy et al, 2007) and immunosuppression associated with organ transplantation (Valar et al, 2007).

c- Visceral larva migrans due to Toxocara canis should be considered in children with a propensity for geophagous pica and ingestion of dirt contaminated by dog Toxocara eggs. Serologic testing confirmed diagnosis. Ocular involvement occurred as the sole manifestation of visceral larva migrans, often presenting in those without an antecedent history of symptomatic visceral larva migrans (Good et al, 2004). Ocular lesion is due to larval localization in the eye and the granulomatous response around the larva. Common symptoms are strabismus and failing vision. Typical lesion is a whitish elevated granuloma measuring 1 to 2 diameters and located in the retina posterior pole. Occasionally, ocular larva migrans may occur as uveitis or endophthalmitis (Stewart et al, 2005). In Egypt, T. canis eggs were detected in $9.83 \%$ of pet dogs (Haridy et al, 2009).

d- Uspensky et al. (2018) in Russia reported that trichinellosis, a zoonotic disease is still a public health concern in the Arctic with highest prevalence among people consuming traditional local foods made from the meat of marine mammals. T. nativa larvae survived for up to 24 months in a fermented and frozen marine mammal meat product called kopalkhen. As larvae life cycle could be completed in absence of humans, it persisted in the environment as a cause of morbidity in human populations living these regions. Despite prominence in infection response to intestine-dwelling worms, $T$. spiralis in eosinophil ablated strains of mice consistently showed that eosinophils do not contribute in a discernable way to intestinal immunity (Svensson et al, 2011). In trichinellosis, eosinophils promo-ted growth and survival of larvae, which colonized skeletal muscle (Gebreselassie et al, 2012). By combining eosinophil ablation $\&$ restoration with the natural infection documented new imm- uno-regulatory eosinophils function in helminthiasis. Eosinophils entered infection sites immediately after tissue invasion by larvae that were essential for their survive (Huang et al, 2014).

e- Filariasis is a vector borne disease especially prevalent in tropical and subtropical regions and caused by slender thread-like filarial worms which has an affinity towards skin and subcutaneous tissue or lymphatic system (WHO, 2012). While Onchocerca volvulus and Loa loa affected the skin, Wuchereria bancrofti, Brugia malayi and Brugia timori cause lymphatic filariasis in the descending order (Oza et al, 2014). W. bancrofti causes a wide range of clinical pictures depending upon its phase and duration. Microfilaremia and paradoxical eosinophilia (lowest count at night) are striking features in the acute phase. Chronic phase is usually characterized by lymphadenopathy in lower limbs, retroperitoneal tissues, lymphedema, hydrocele and elephantiasis (Abdel-Shafi et al, 2017).

In contrast to infections with multicellular helminthic parasites, infections with singlecelled protozoan parasites, including enteric Giardia lamblia and Entamoeba histolytica, do not characteristically elicit blood eosinophilia. Identification of these protozoa in stool examinations did not complete a diagnostic workup for eosinophilia since other potential pathogens should still be sought (Nutman, 2006). There are two exceptions to general rule that protozoa, including those in the GI tract, do not elicit eosinophilia: Dientamoeba fragilis and Isospora belli. Thus, in patients with symptoms of enteric infection (loose stools or diarrhea) and eosinophilia, diagnostic trophozoites of $D$. fragilis or oocysts of $I$. belli must be sought in stool examinations. Diarrhea was $38.5 \%$ of Egyptian patients infected with $D$. fragilis compared to $50 \%$ of patients infected with G. lamblia, while abdominal pain was in significanlty encountered with $D$. fragilis in $41 \%$ compared to $33.3 \%$ with G. lamblia (Rayan et al, 2007). Eassa et al. (2016) in Alexandria re- 
ported that about half of 346 municipality solid-waste workers, apart from helminthes, were infected with E. histolytica (3.2\%), G. lamblia (2.9\%), Cryptosporidium (23.4\%), Microsporidia (20.25\%), Cyclospora spp. (2.0\%), B. hominis (1.7\%), and Cystoisospora belli $(1.2 \%)$.

Laboratory evaluation: Differential diagnosis can be narrowed based upon clinical findings and geographic considerations. Depending on travel history, stool examination for ova and parasites should be done when certain helminthiasis are encountered (as Strongyloides sp., Hookworm, Fasciolopsis buski, Clonorchis sinensis). In the case of light infections, multiple stools may need to be examined.

Patients with negative stool examinations may have tissue- or blood-dwelling helminthic infections that require serologic tests for diagnosis as Trichinella spiralis, Wuchereria bancrofti, Toxocara canis, Schistosoma sp., Echinococcus sp. (Plumelle et al, 1997).

Urine sedimentation can be considered for suspected Schistosoma haematobium or in the setting of chyluria due to W. bancrofti. Also, sputum analysis must be ordered for suspected pulmonary infection with Strongyloides sp. or Paragonimus sp.

The optimal management of asymptomatic traveler or immigrant with eosinophilia is uncertain. Up to $50 \%$ of patients never have a cause of their eosinophilia identified despite exhaustive evaluation (Libman et al, 1993). Others suggested a strategy of using empiric anthelminthic therapies (Muennig et $a l, 1999)$.

Miscellaneous causes: 1- Adrenal insufficiency: The loss of endogenous glucocorticoids in any cause of adrenal insufficiency results in blood eosinophilia. Glucocorticoids exert eosinopenic effects, at least in part by stimulating eosinophil, but not neutronphil, apoptosis (Meagher et al, 1996). The presence of relative eosinophilia in critically ill patients was associated with clinical signs of relative adrenal insufficiency. Among 612 consecutive admissions to a medical-surgi- cal intensive care unit, 40/570 assessable patients $(7 \%)$ had relative eosinophilia more than 3\% (Beishuizen et al, 1999). Low-dose adrenocorticotropin stimulation testing was abnormal in $10 / 40$ patients $(25 \%)$. Clinical suspicion of adrenal insufficiency was high in $8 / 10$ patients, and treatment with hydrocortisone resulted in hemodynamic improvement in seven. Sakao et al. (2014) in Japan analyzed retrospectively the clinical characteristics of five HD patients who were presented with hypercalcemia due to adrenal insufficiency (age: 69 \pm 7 ), time on HD: $13 \pm 11$ years old. All patients had critical illnesses at hypercalcemia onset, with at least one symptom, such as eosinophilia, hypoglycemia, or fever. Hypercalcemia prevalence due to adrenal insufficiency was $1.3 \%$ in maintenance HD patients on admission. The causes of adrenal insufficiency were isolated ACTH deficiency, pituitary apoplexy, pituitary atrophy, glucocorticoid withdrawal syndrome, \& unilateral adrenalectomy. Serum calcium levels corrected by serum albumin were maximally increased to 12.9 to 14.3 $\mathrm{mg} / \mathrm{dL}$ in four anuric HD patients and mildly elevated to $10.4 \mathrm{mg} / \mathrm{dL}$ in a patient with residual diuresis. Basal serum cortisol levels ranged from $<1.0$ to $15.4 \mu \mathrm{g} / \mathrm{dL}$. Single $\mathrm{CRH}$ injections failed to increase serum cortisol in any of the patients. Glucocorticoid replacement acutely normalized serum $\mathrm{Ca}$ and decreased levels of carboxy-terminal telopeptide of type I collagen, a marker of bone resorption. They concluded that adrenal insufficiency was an occult cause of hypercalcemia in anuric HD critically ill patients

2- Atheroembolic disease: Cholesterol embolization could lead to an increased erythrocyte sedimentation rate, hypocomplementemia, thrombocytopenia, eosinophilia, eosinophiluria, renal insufficiency, livedo reticularis, and/or purple toes (Wilson et al, 1991) Blood eosinophilia might be the sole clinical clue to this disorder (Levine et al, 1992). Murono et al. (2018) found that cholesterol crystal embolism (CCE) was caused by sma11 cholesterol crystals dispersed from athero- 
sclerotic plaques of the aorta. There was an increasing in CCE because of increased use of endovascular treatments. They reported an intestinal anastomotic stenosis as a rare CCE case. Intestinal CCE was difficult to diagnose preoperatively and associated with poor prognosis. When eosinophilia or shaggy aorta was observed, CCE must be suspected to reach an accurate diagnosis and reduce the recurrence risk.

3- Immunodeficiency states: Some primary immunodeficiency syndromes are associated with eosinophilia, including the hyper-IgE syndrome; characterized by chronic dermatitis and re-current infections (Hochreutener et al, 1991) and Omenn's syndrome; combined immune-deficiency with hypereosinophilia (Schandené et al, 1993). Thymoma was associated with bone marrow eosinophilia (Fitzmaurice and Gardner, 1990). A syndrome of recurrent staphylococcal abscesses, sinopulmonary infections, and severe eczema, initially called Job Syndrome, based upon a description of the biblical character Job: "so went Satan forth from the presence of the Lord and smote Job with sore boils from the sole of his foot unto his crown" (Job, II, 7). The cutaneous abscesses in patients appeared cold or, lacked the typical inflammation signs. It was speculated that immune defect in Job syndrome lay in an abnormality in nonspecific mechanisms of local bacterial resistance and perhaps in abnormalities of mediators of acute inflammatory response that was termed hyperimmunoglobulin E syndrome (HIES) when an associated increase in serum levels of $\operatorname{IgE}$ was described (Buckley et al, 1972). Also, elevated levels of serum IgE, there were intermittent defects in polymorphonuclear leukocyte chemotaxis and associated immune regulatory defects. Dominant-negative mutations in the DNA-binding domain of signal transducer and activator of transcription 3 (STAT3) caused the autosomal dominant form of hyperimmunoglobulin IgE syndrome (Holland et al, 2007). A homozygous null mutation in tyrosine kinase 2 (TYK2) was identified in one patient with autosomal recessive HIES (Minegishi et al, 2006). Infectious pulmonary complications was fatal in patients with HIE syndrome, followed by lymphoma. Pneumatoceles caused subsequent pneumonia, systemic infection, and/or sudden pulmonary hemorrhage. Vascular invasion by fungi raised mycotic aneurysms with lungs and other organs hemorrhagic complications. Pneumatoceles colonise with fungi \& gram negative bacteria; including Aspergillus fumigatus and Pseudomonas aeruginosa (Freeman et al, 2007).

$\mathrm{T}$ cell negative, $\mathrm{B}$ cell negative, NK cell positive severe combined immunodeficiency: An extreme form of severe combined immunodeficiency disease (SCID) is $\mathrm{T}$ cell negative (T-), B cell negative (B-), natural killer cell positive $(\mathrm{NK}+)$ SCID phenotype accounted for 20 to $30 \%$ of all SCID cases (Stephan et al, 1993). Children with T-BNK+ SCID present early in life with serious infections, failure to thrive, low to absent $\mathrm{T}$ and $\mathrm{B}$ cell numbers \& function, and normal numbers and function of natural killer (NK) cells. Defects in at least five autosomal recessive genes in man and one in animals, all involved in $\mathrm{V}(\mathrm{D}) \mathrm{J}$ recombination, resulted in this form of SCID (Meek et al, 2001). Since some of the proteins encoded by genes were involved in DNA repair, defects in pathways were associated with radiation/chemothera py sensitivity. Genetic mutations, both naturally occurred and engineered, resulted in a better known of this critical step in T \& B cell maturation (van der, Burg et al, 2009). No conditioning or immunosuppressive conditioning alone (low cyclophosphamide) for initial HCT in children with non-RAG1 or RAG2 types of T-B-NK+SCID) was a must. Donor marrow 'boosts' or repeat BMT with myeloablative conditioning must be reserved for those with initial procedure results in inadequate $\mathrm{T}$ cell immune reconstitution or graft failure (Kwan and Puck, 2015).

\section{Conclusion}

An increase in eosinophils in blood occurs in response to some allergens, drugs, parasit- 
es, and some types of leukemia. It is host immune response to distinguish helminthic infections from others, yet eosinophils discrete function in worms is elusive.

Eosinophils help promote inflammation with a beneficial role in isolating and controlling a disease site. Sometimes inflammation may be greater than is necessary, which can lead to troublesome symptoms or even tissue damage

\section{References}

Abdel-Shafi, IR, Shoieb, EY, Attia, SS, Rubio, JM, Ta-Tang, TH, El-Badry, AA, 2017: Molecular identification and phylogenetic analysis of Wuchereria bancrofti from human blood samples in Egypt. Parasitol. Res. 116, 3:963-70.

Bain, BJ, 1996: Eosinophilic leukaemias and the idiopathic hypereosinophilic syndrome. $\mathrm{Br}$. J. Haematol. 95:2-8.

Bain, BJ, Fletcher, SH, 2007: Chronic eosinophilic leukemias and the myelo-proliferative variant of the hypereosinophilic syndrome. Immunol. Aller. Clin. North Am. 27:377-82.

Bayhan, Gİ, Batur, A, Taylan-Özkan, A, Demirören, K, Beyhan, YE, 2016: A pediatric case of fascioliasis with eosinophilic pneumonia. Turk. J. Pediatr. 58, 1:109-12.

Bass, DA, Gonwa, TA, Szejda, P, et al, 1980: Eosinopenia of acute infection: Production of eosinopenia by chemotactic factors of acute inflammation. J. Clin. Invest. 65:1265-70.

Beishuizen, A, Vermes, I, Hylkema, BS, Haanen, C, 1999: Relative eosinophilia and functional adrenal insufficiency in critically ill patients. Lancet 353:1675.

Bhatt, NY, Allen, JN, 2012: Update on eosinophilic lung diseases. Semin. Respir. Crit. Care Med. 33:555-71.

Blauwet, LA, Breen, JF, Edwards, WD, Klarich, KW, 2005: Atypical presentation of eosinophilic endomyocardial disease. Mayo Clin. Proc. 80:1078-86.

Brito-Babapulle, F, 2003: Eosinophilias, including the idiopathic hypereosinophilic syndrome. Br. J. Haematol. 121:203-6.

Brown, M, Cartledge, J, Miller, R, 2006: Dissemination of Strongyloides stercoralis as an immune restoration phenomenon in an HIV-1- infected man on antiretroviral therapy. Int. J. STD AIDS 17:560-4.

Buckley, RH, Wray, BB, Belmaker, EZ, 1972:
Extreme hyperimmunoglobulinemia E \& undue susceptibility to infection. Pediatrics 49:59-62.

Carvalho, EM, Da Fonseca, Porto A, 2004: Epidemiological and clinical interaction between HTLV-1 and Strongyloides stercoralis. Parasite Immunol. 26, 11/12:487-97.

Concha, R, Harrington, WJr, Rogers, AI, 2005: Intestinal strongyloidiasis: Recognition, management, and determinants of outcome. J. Clin. Gastroenterol. 39:203-9

Eassa, SM, El-Wahab, EW, Lotfi, SE, EI Masry, SA, Shatat, HZ, et al, 2016: Risk factors associated with parasitic infection among municipality solid-waste workers in an Egyptian community. J. Parasitol. 102, 2:214-21.

Fitzmaurice, RJ, Gardner, DL, 1990: Thymoma with bone marrow eosinophilia. J. Roy. Soc. Med. 83:270-4.

Freeman, AF, Kleiner, DE, Nadiminti, H, et al, 2007: Causes of death in hyper-IgE syndrome. J. Allergy Clin. Immunol.119:1234-8.

Fürst, T, Duthaler, U, Sripa, B, Utzinger, J, Keiser, J, 2012: Trematode infections. Infect. Dis. Clin. North Am. 26: 399-419.

Gebreselassie, NG, Moorhead, AR, Fabre, V, Gagliardo, LF, Lee, NA, et al, 2012: Eosinophils preserve parasitic nematode larvae by regulating local immunity. J. Immunol. 188:417-25. Georgiou, S, Maroulis, J, Monastirli A, et al, 2005: Anaphylactic shock as the only clinical manifestation of hepatic hydatid disease. Int. J. Dermatol. 44:233-9.

Gill, GV, Bailey, JW, 1989: Eosinophilia as a marker for chronic strongyloidiasis-use of a serum ELISA test to detect asymptomatic cases. Ann. Trop. Med. Parasitol. 83:249-54.

Good, B, Holland, CV, Taylor, MR, et al, 2004: Ocular toxocariasis in schoolchildren. Clin. Infect. Dis. 39:173-8.

Gryseels, B, Polman, K, Clerinx, J, Kestens, L, 2006: Human schistosomiasis. Lancet 368 , 9541:1106-18.

Haridy, FM, Hassan, AA, Hafez, AO, El-Sherbini, GT, Morsy, TA, 2009: External and intestinal parasites of pet dogs with reference to zoonotic toxocariasis. J. Egypt. Soc. Parasitol. 39, 1:321-6.

Hochreutener, H, Wüthrich, B, Huwyler, T, et al, 1991: Variant of hyper-IgE syndrome: The differentiation from atopic dermatitis is important because of treatment and prognosis. Dermatol. 182:7-9. 
Holland, SM, DeLeo, FR, Elloumi, HZ, et al, 2007: STAT3 mutations in the hyper-IgE syndrome. N. Engl. J. Med. 357:1608-12.

Huang, L, Gebreselassie, NG, Gagliardo, LF, Ruyechan, MC, Lee, NA, et al, 2014: Eosinophil-derived IL-10 supports chronic nematode infection. J. Immunol. 193, 8:4178-87.

Hwang, KJ, Heo, SH, Chang, DI, 2012: Multiple microembolic brain infarctions in Clonorchis sinensis infection. J. Neurol. Sci. 319, 1/2:133-4. Jenerowicz, D, Czarnecka-Operacz, M, Silny, W, 2007: Peripheral blood eosinophilia in atopic dermatitis. Acta Dermatovenerol. Alp Panonica Adriat. 16:47-52.

Kaya, M, Beştaş, R, Cetin, S, 2011: Clinical presentation and management of Fasciola heaptica infection: single-center experience. World J. Gastroenterol. 28, 17:4899-904.

Keiser, PB, Nutman, TB, 2004: Strongyloides stercoralis in the immunocompromised population. Clin. Microbiol. Rev. 17:208-12.

Kim, AC, Lupatkin, HC, 2004: Strongyloides stercoralis infection as a manifestation of immune restoration syndrome. Clin, Infect. Dis. 39: 439-42.

Krishnamurthy, R, Dincer, HE, Whitmore, D, 2007: Strongyloides stercoralis hyperinfection in a patient with rheumatoid arthritis after anti-TNF -alpha therapy. J. Clin. Rheumatol. 13: 150-4.

Levine, J, Rennke, HG, Idelson, BA, 1992: Profound persistent eosinophilia in a patient with spontaneous renal atheroembolic disease. Am. J. Nephrol.12:377-82.

Libman, MD, MacLean, JD, Gyorkos, TW, 1993: Screening for schistosomiasis, filariasis, and strongyloidiasis among expatriates returning from the tropics. Clin. Infect. Dis. 17:353-8.

Liu, Z, Liu, Q, Pesce, J, et al, 2004: Requirements for the development of IL-4-producing $\mathrm{T}$ cells during intestinal nematode infections: what it takes to make a Th2 cell in vivo. Immunol. Rev. 201:57-62.

Lombardi, C, Passalacqua, G, 2003: Eosinophilia and diseases: Clinical revision of 1862 cases. Arch. Intern. Med. 163:1371-7.

Meagher, LC, Cousin, JM, Seckl, JR, Haslett, C, 1996: Opposing effects of glucocorticoids on rate of apoptosis in neutrophilic and eosinophilic granulocytes. J. Immunol. 156:4422-6.

Meek, K, Kienker, L, Dallas, C, et al, 2001: SCID in Jack Russell terriers: A new animal model of DNA-PKcs deficiency. J. Immunol. 167: 2142-8.
Minegishi, Y, Saito, M, Morio, T, et al, 2006: Human tyrosine kinase 2 deficiency reveals its requisite roles in multiple cytokine signals involved in innate and acquired immunity. Immunity 25:745-8.

Moorhead, A, Grunenwald, PE, Dietz, VJ, Schantz, PM, 1999: Trichinellosis in the United States, 1991-1996: declining but not gone. Am. J. Trop. Med. Hyg. 60:66-70.

Morsy, AT, Al-Mathal, EM, 2011: Clonorchis sinensis a new report in Egyptian employees returning back from Saudi Arabia. J. Egypt. Soc. Parasitol. 41, 1:221-5.

Muennig, P, Pallin, D, Sell, RL, Chan, MS, 1999: The cost effectiveness of strategies for treatment of intestinal parasites in immigrants. $\mathrm{N}$. Engl. J. Med. 340:773-9.

Murono, K, Kawai, K, Hata, K, Emot, S, Kaneko, M, et al, 2018: A case of anastomotic stenosis of the small intestine caused by cholesterol crystal embolism. Surg. Case Rep. 4, 1:29-32.

Murrell, KD, Pozio, E, 2000: Trichinellosis: Zoonosis that won't go quietly. Int. J. Parasitol. 30:1339-44.

Noh, G, Jin, H, Lee, J, et al, 2010: Eosinophilia as a predictor of food allergy in atopic dermatitis. Allergy Asthma Proc. 31:e18.

Nucci, M, Portugal, R, Pulcheri, W, et al, 1995: Strongyloidiasis in patients with hematologic malignancies. Clin. Infect. Dis. 21:675-80.

Nutman, TB, 2006: Asymptomatic peripheral blood eosinophilia redux: Common parasitic infections presenting frequently in refugees and immigrants. Clin. Infect. Dis. 42:368-72.

Nutman, TB, Ottesen, EA, Ieng, S, et al, 1987: Eosinophilia in Southeast Asian refugees: Evaluation at a referral center. J. Infect. Dis. 155: 309-12.

Oza, H, Bhalodia, J, Shah, A, Modi, P, 2014: Mid-arm swelling-A rare presentation of filariasis. Natl. J. Med. Res. 4, 3:256-8.

Paganelli, R, Scala, E, Mezzaroma, I, et al, 1995: Immunologic aspects of hyperimmuno-globulinemia E-like syndrome in patients with AIDS. J. Aller. Clin. Immunol. 95:995-1002.

Pardo, J, Carranza, C, Muro, A, et al, 2006: Helminth-related eosinophilia in African immigrants, Gran Canaria. Emerg. Infect. Dis. 12:1587 Plumelle, Y, Gonin, C, Edouard, A, et al, 1997: Effect of Strongyloides stercoralis and eosinophilia on age at onset and prognosis of adult T-cell leukemia. Am. J. Clin. Pathol. 107:81-6. Rashed, AA, Khalil, HHM, Morsy, AT, 2010: 
Zoonotic ectopic fascioliasis: Review and discussion. J. Egypt. Soc. Parasitol. 40, 3:591-608

Rayan, HZ, Ismail, OA, EI Gayar, EK, 2007: Prevalence and clinical features of Dientamoeba fragilis infections in patients suspected to have intestinal parasitic infection. J. Egypt. Soc. Parasitol. 37, 2:599-608.

Roufosse, F, Weller, PF, 2010: Practical approach to the patient with hypereosinophilia. J. Aller. Clin. Immunol. 126:39-42.

Sakao, Y, Sugiura, T, Tsuji, T, Ohashi, N, Yasuda, H, et al, 2014: Clinical manifestation of hyper-calcemia caused by adrenal insufficiency in hemodialysis patients: a case-series study. Int. Med. 53, 14:1485-90.

Schandené, L, Ferster, A, Mascart, F, et al, 1993: $T$ helper type 2-like cells and therapeutic effects of interferon-gamma in combined immunodeficiency with hypereosinophiliabi (Omenn's syndrome). Eur. J. Immunol. 23:56-9.

Sheikh, J, Weller, PF, 2007: Clinical overview of hypereosinophilic syndromes. Immunol. Aller. Clin. North Am. 27:333-42.

Simon, HU, Rothenberg, M, Bochner, B, et al, 2010: Refining definition of hypereosinophi- lic syndrome. J. Aller. Clin. Immunol. 126:45-50.

Stewart, JM, Cubillan, LD, Cunningham, ET, 2005: Prevalence, clinical features, and causes of vision loss among patients with ocular toxocariasis. Retina 25:1005-8.

Svensson, M, Bell, L, Little, MC, DeSchoolmeester, M, Locksley, RM, et al, 2011: Accumulation of eosinophils in intestine-draining mesenteric lymph nodes occurs after Trichuris mu- ris infection. Parasit. Immunol. 33:1-11.

Szor, DJ, Dias, AR, Pereira, MA, Ramos, MF KP, Zilberstein, B, et al, 2018: Prognostic role of neutrophil/lymphocyte ratio in resected gastric cancer: A systematic review and meta-analysis. Clin. (Sao Paulo) 73:e360. doi: 10.6061/ clinics/ 2018/e360.

Uspensky, A, Bukina, L, Odoevskaya, I, Movssesyan, S, Voronin, M, 2018: The epidemiology of trichinellosis in the Arctic territories of a far eastern district of the Russian Federation. J. Helminthol. 31:1-8.

Valar, C, Keitel, E, Dal Pra, RL, et al, 2007: Parasitic infection in renal transplant recipients. Transplant. Proc. 39:460-5.

van der, Burg M, Ijspeert, H, Verkaik, NS, et al, 2009: A DNA-PKcs mutation in a radiosensitive T-B-SCID patient inhibits Artemis activetion and non-homologous end-joining. J. Clin. Invest. 119:91-8.

Viney, M, Brown, M, Omoding, N, et al, 2004: Why does HIV infection not lead to disseminated strongyloidiasis? J. Infect. Dis. 190: 2175-9. Weller, PF, 1991: The immunobiology of eosinophils. N. Engl. J. Med. 324:1110-2.

WHO, 2012: Annual Country Reports. who.int/ mapLibrary/Files/Maps/LF_2012.png.

Wilson, DM, Salazer, TL, Farkouh, ME, 1991: Eosinophiluria in atheroembolic renal disease. Am. J. Med. 91:186.

Winchester, RJ, Koffler, D, Litwin, SD, Kunkel, HG, 1971: Observations on the eosinophilia of certain patients with rheumatoid arthritis. Arthritis Rheum. 14:650-4

Table 1: Helminthic diseases causing marked eosinophilia $(>3000 / \mu \mathrm{L})$ after (Weller, 1991).
\begin{tabular}{|l|l|}
\hline \multicolumn{1}{|c|}{ Parasite } & Notes \\
\hline Angiostrongyliasis costaricensis & \\
\hline Ascariasis & Early transpulmonary larval migration, often absent when mature \\
\hline Hookworm infection & Early transpulmonary larval migration, often mild when mature \\
\hline Strongyloidiasis, Trichinosis, Gnathostomiasis & \\
\hline Visceral larva migrans & Primarily in children \\
\hline Filaria Tropical pulmonary eosinophilia & Especially in expatriates \\
\hline Loiasis, Onchocerciasis & \\
\hline Schistosomiasis & During early infection in non-immunes (Katayama fever) \\
\hline $\begin{array}{l}\text { Fascioliasis, Fasciolopsiasis, Clonorchiasis, } \\
\text { Paragonimiasis, }\end{array}$ & During early infection \\
\hline
\end{tabular}

\begin{tabular}{|l|l|}
\hline \multicolumn{2}{|c|}{ Table 2: Helminthtic diseases causing eosinophilia of years' duration (Weller, 1992). } \\
\hline \multicolumn{1}{|c|}{ Parasite } & Notes \\
\hline Hookworm infection & Common cause of low-grade eosinophilia \\
\hline Strongyloidiasis & Self-perpetuating, auto-infection cycle; may last >50 yrs. \\
\hline Cysticercosis, Echinococcosis, Gnathostomiasis & Especially in expatriates \\
\hline Filaria Tropical pulmonary eosinophilia & \\
\hline $\begin{array}{l}\text { Loiasis, Onchocerciasis, Mansonelliasis, Schistoso- } \\
\text { miasis, Fascioliasis, Clonorchiasis, Paragonimiasis }\end{array}$ & \\
\hline
\end{tabular}

